\title{
REFLEXIONES Y PROBLEMÁTICAS EN TORNO AL ESTUDIO DE LOS SIGNOS RUPESTRES PALEOLÍTICOS
}

\author{
Reflections and problems concerning the study \\ of palaeolithic rock signs
}

\author{
Alberto Mingo Álvarez* \\ Recibido el 28 de noviembre de 2007. Aceptado el 10 de octubre de 2008.
}

Resumen. Las representaciones de signos han sido frecuentemente relegadas a un segundo plano por la historiografia del arte paleolítico que ha dado preferencia al estudio de las figuras zoomorfas y antropomorfas. Sin embargo, desde mediados del siglo XX ha ido paulatinamente incrementando la importancia que los investigadores conceden a estas imágenes. Su predominio cuantitativo en un buen número de estaciones rupestres, su variada morfología y sus heterogéneas disposiciones contextuales son aspectos que confieren a esta categoría temática una gran complejidad. En este trabajo, se plantean una serie de reflexiones y problemáticas que, desde nuestra perspectiva, surgen inevitablemente cuando nos enfrentamos al estudio y documentación de los signos rupestres paleolíticos. Igualmente, se desarrolla la relevancia que está adquiriendo el enfoque investigador que defiende el valor de los paralelismos de las imágenes paleoliticas, especialmente en los signos, como uno de los aspectos fundamentales para identificar no solo la sincronía de los conjuntos y la existencia de semejantes mundos ideológicos sino también la territorialidad de los grupos humanos pleistocénicos.

Palabras clave: Signos. Arte rupestre paleolítico. Ideología. Territorialidad.

Abstract. The representations of signs have been frequently relegated to a background by the historiography of the paleolithic art that has given preference to the study of the zoomorphic and anthropomorphous figures. Nevertheless, from middle of the 20th century the importance that researchers grant to these images has been increasing gradually. Their quantitative predominance in a good number of rock sites, their varied morphology and their heterogeneous contextual situations are aspects that provide a great complexity to this thematic category. Under our point of view, the reflections and problems posed in this work arise inevitably when we face the study and documentation of paleolithic rock signs. Equally, we bring up the relevancy that is acquiring the investigative approach defending the value of parallelisms in paleolithic images, specially in signs, as one of the fundamental aspects to identify not only the synchrony of sets and the existence of similar ideological worlds but also the territoriality of pleistocenic human groups.

Key Words: Signs. Palaeolithic rock art. Ideology. Territoriality.

\section{INTRODUCCIÓN}

La historiografía del fenómeno llamado arte paleolítico ha reconocido, de un modo general y erróneo, que la temática de estas expresiones gráficas giraba en torno a tres categorias básicas: animales, motivos antropomorfos y signos. Desde los primeros descubrimientos de piezas decoradas mobiliares y posteriormente con la aparición y aceptación de las imágenes parietales se extendió el convencimiento de que se trataba de un fenómeno figurativo en donde predominaban las figuras zoomorfas, en especial los herbivoros, muy por encima de las otras dos categorías. El testimonio de S. Reinach así lo corrobora, "...he constatado primeramente que los motivos referentes al mundo animal son con mucho los más numerosos; los animales representados son, a título exclusivo, aque-

(*) Dpto. Prehistoria y Arqueología. UNED. Senda del Rey, 7. 28040 Madrid. E-mail: amingo@geo.uned.es 
Ilos de los que se nutre un pueblo de cazadores recolectores" (Reinach, 1903: 258). Esta idea perduró hasta casi finales del siglo XX, donde no eran infrecuentes afirmaciones como: "El artista trata de representar el mundo exterior, la realidad de su quehacer diario, la caza o mejor dicho el producto de la misma: el animal" (Jordá, 1964; citado en Casado, 1977: 13). La creencia en la existencia de una esencia "faunística" del fenómeno conllevó desde las primeras publicaciones una atracción investigadora hacia este tipo de imágenes, dejando a un lado y subyugando el resto de categorías, que pasan a ocupar un lugar subsidiario. La importancia otorgada a los signos podía aumentar si estaban próximos o se podian poner en relación con otras figuras animales "... o con la finalidad de dar una interpretación al conjunto del arte" (Casado, 1977: 13). Los estudios modernos de las cuevas, más sistemáticos, estructurados y globales que los iniciales, han puesto de manifiesto lo errado de la perspectiva anterior.

Los primeros investigadores, apoyándose en comparaciones etnológicas, sostenían que muchos de estos signos tenían un modelo auténtico en la realidad, es decir, estaban reflejando un objeto o un elemento real. Sin análisis minuciosos, ni la necesaria prudencia, se embarcaron en la tarea de identificar y "bautizar" signos bajo un prisma subjetivo. Actualmente los análisis proyectan una realidad de la iconografía rupestre paleolítica bien diferente a este respecto: "Paradójicamente y desde una óptica numérica son más abundantes y diversificados (los signos) que el resto de los temas $y_{1}$ por tanto, más representativos del arte que tratamos; en ciertas cuevas son poco menos que exclusivos, y en consecuencia siempre estaremos tentados de afirmar que el arte parietal paleolítico se caracteriza por la plasmación de signos" (Sanchidrián, 2001: 246). Una vez que los signos, y esto se debe en buena medida al ingente trabajo de A. Leroi-Gourhan y al papel central que otorgó a estas representaciones, tuvieron su reconocimiento, se ha asumido ese desplazamiento analítico injusto y han comenzado a gozar de un mayor protagonismo en la investigación: "Descuidados durante largo tiempo, estos motivos de tipo geométrico aparecen, en realidad, no solo como mucho más numerosos, sino también como mucho más variados que las representaciones zoomorfas" (Groenen, 2000: 41). Estas inferencias se demuestran con los datos en la mano, así D. Vialou (1986: 350), en un estudio global sobre las cuevas (11 en total) con representaciones paleolíticas de la región de L'Ariège, en el Pirineo oriental francés, calcula que de las 2600 unidades gráficas atestiguadas, 1400 son signos; M. Lorblanchet (1989: 88) constata como en la cueva de Pech Merle, en la región del Lot (Francia), de 662 motivos se han registrado 562 signos, mientras que en la gruta de Cougnac, próxima a aquella, de 305 figuras, un porcentaje superior al 80\% lo constituyen los signos; Sanchidrián (2001: 246) reconoce que en Andalucía un buen número de composiciones parietales de supuesta cronología solutrense contienen proporciones de entre el 92-99\% de estas imágenes. Esta variación y cantidad se deben indiscutiblemente al criterio de exclusión que define a esta categoria, que está formada por manifestaciones que comparten la imposibilidad actual de vinculación "figurativa".

La heterogeneidad en las formas y los contextos donde aparecen, la cantidad presente y la complejidad morfológica e incluso técnica de algunos de estos signos, dibujan un panorama de este fenómeno en el que se debe admitir un papel preponderante a estas representaciones en su globalidad. Como elementos gráficos activos de mensajes construidos en un proceso comunicativo de la sociedad paleolítica es absolutamente innegable que cada imagen (representación expresiva de signos, animales, antropomorfos, etc.) por insignificante que pudiera parecer tiene su importancia.

En definitiva, la constatación en el registro de conjuntos únicamente formados por signos; otros en los que no se puede distinguir con certeza si éstos han sido realizados en conjunción con otras figuras o bien si conforman composiciones aisladas $^{1}$; y otros donde los paneles de estas representaciones son alternados con figuras de animales, evidenciando unas diferencias técnicas notables y un distinto patrón en cuanto a las superposiciones, sugiere que en ciertos períodos de decoración de algunas cavidades los signos fueron las únicas imágenes plasmadas o las dominadoras dentro de los registros. De modo que se podría desmontar fácilmente una de las "generalizaciones simplificadoras" heredadas y aceptadas en el acervo común del arte paleolítico: los signos serian meros acompañantes de las simbólicamente más importantes figuras animales (González Morales, 1994; 297).

\section{APROXIMACIONES HISTORIOGRÁFICAS AL ESTUDIO DE LOS SIGNOS: LAS CLASIFICACIONES}

"Porque su significado es incierto, la comprensión intuitiva de las figuras no puede usarse para la identificación de signos. Es extremadamente difícil clasificar los numerosos, a menudo únicos, motivos en conjuntos que puedan ser considerados como unidades significantes" (Layton, 1987: 220). Los investigadores han adoptado en su aproximación al estudio de estas formas dos diferentes perspectivas, parcialmente influenciados por su interpretación de este fenómeno en conjunto. Por un lado, los especialistas de la primera mitad del siglo XX, con H. Breuil a la cabeza, procuraban descubrir parecidos o semejanzas de esas imágenes con objetos o estructuras materiales reales. De este modo, por ejemplo, surgieron los signos "tectiformes" (por apreciarse en ellos una

(') Como sucede en un buen número de casos en la zona cantábrica (Mazaculos, Balmori, La Herrería en Asturias; Santían, Fuente del Salín, El Calero, El Cudón en Cantabria; entre otras). 


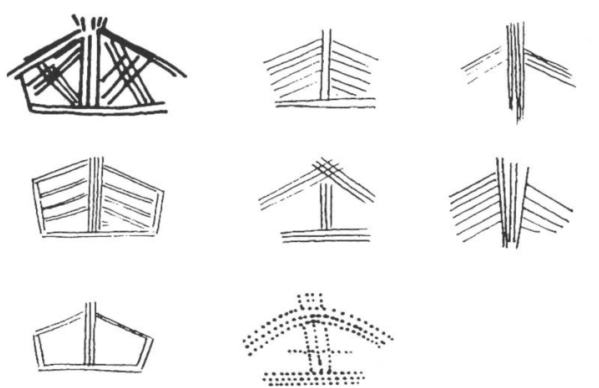

$\Delta$ FiguRa 1. Diferentes tipos de signos "tectiformes" de la región de Perigord (Francia).

posible cabaña con un techo saliente) (fig. 1), "claviformes" (por atisbarse en ellos un diseño de clavos), "aviformes" (por asemejarse supuestamente a aves), "escutiformes" (por recordar e escudos), "laciformes" (por parecerse a lazos), etc. Por otro lado, se encuentran las clasificaciones más recientes (Sauvet, 1977; Casado, 1977; Vialou, 1986, Sanchidrián, 1994) que se basan en criterios estrictamente morfológicos y rechazan expresamente emitir y conjeturar identificaciones y con ello apuntar a un significado. No obstante, a pesar del esfuerzo de los especialistas que defienden una nomenclatura más morfológica (generalmente geométrica), lo cierto es que los nombres heredados tienen tal raigambre entre la comunidad investigadora que debemos resignarnos a asumir, muy probablemente, una larga vigencia de los mismos.

La transición entre el modelo clasificatorio, llamémosle, de "semejanza" de los primeros tiempos y el modelo morfológico empleado más recientemente lo encarna el estudio que $A$. Leroi-Gourhan llevo a cabo sobre los signos (figs. 2 y 3 ). Podría decirse que las posteriores sistematizaciones se nutren de las modalidades que él definió, al ser éstas construidas sobre una base morfológica. Sin embargo, a diferencia de las posteriores, en su clasificación se manifiesta un considerable influjo de su teoría interpretativa. Este vínculo clasificación / interpretación es primordialmente el aspecto que le une con los iniciales intentos sistematizadores. A diferencia del modelo de A. LeroiGourhan, los especialistas que vinieron tras él y que, por otra parte, desarrollaron sus trabajos desde una misma concepción estructuralista, establecieron los tipos en función de las morfologías y de la variedad regional, dejando a un lado aparentemente sus inclinaciones de significado.

En nuestra opinión, el modelo más aséptico y científico de clasificación de estas imágenes en concreto es el que sigue unas pautas exclusivamente tipológicas. Los trabajos de G. Sauvet (1977) (figs. 4 y 5), D. Vialou (1986) (fig. 6) y P. Casado (1977) (fig. 7) serían idóneos, ya que dejan a un lado aquellas comparaciones libres de los primeros tiempos que sin fundamentos suficientemente consistentes se sostenían. Muy posiblemente (consciente o inconscientemente) tales comparaciones pretendían dar más solidez a la teoría en boga en aquellos momentos: la magia de la caza y de la fertilidad.
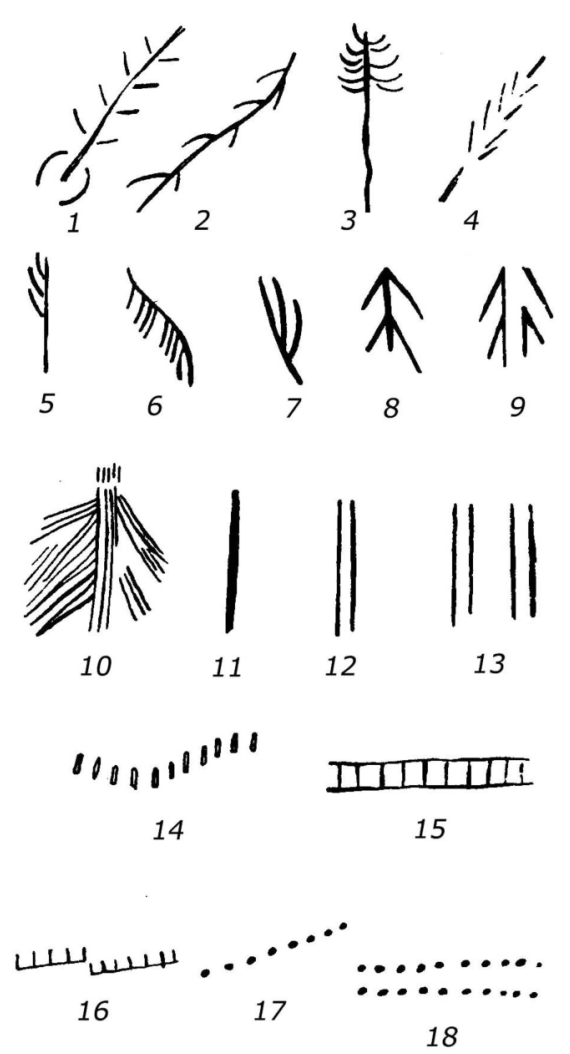

- Figura 2. Serie de signos tenues (interpretados como masculinos) de A. Leroi-Gourhan.
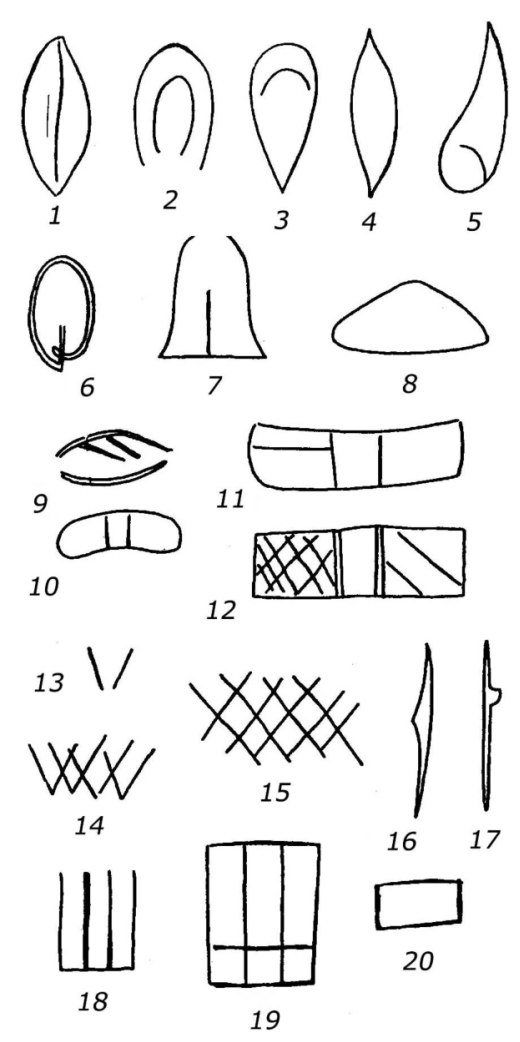

- Figura 3. Serie de signos plenos (interpretados como femeninos) de A. Leroi-Gourhan. 
En opinión de D. Vialou "...Los signos deben ser estudiados por sí mismos en el ámbito concreto de cada cavidad para conseguir una primera tipología de cada estación rupestre" (Vialou, 1986: 347), con el fin de evitar las dificultades que se puedan presentar para encajar formas en clasificaciones tipológicas realizadas para otras regiones y así no dar lugar a posibles distorsiones en los "hechos" gráficos. De igual modo, todos los signos deberían ser estudiados concediéndoles gran relevancia y no dar prioridad a arbitrarias subcategorías (signos "complejos") y discriminar otras (como los trazos, manchas y puntos). Para este investigador, los signos más "simples" tienen "un lugar bien mar-

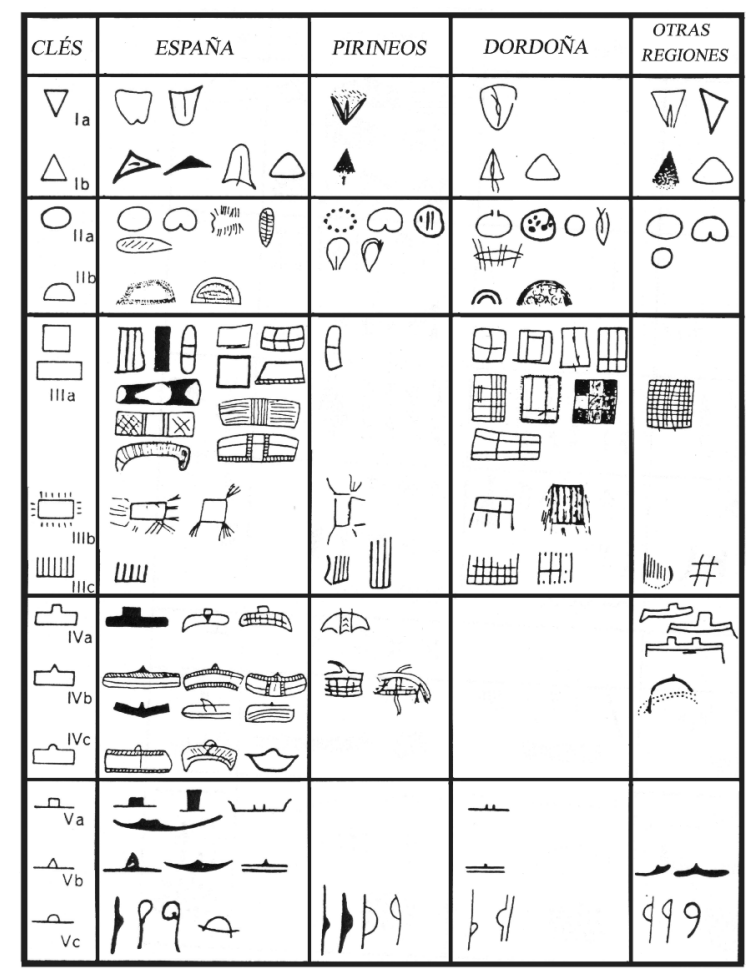

$\Delta$ Figura 4. Clasificación morfológica de G. Sauvet, S. Sauvet y A. Wlodarczyc (1977) I-V “Clés".

\begin{tabular}{|c|c|c|c|c|}
\hline CLÉS & ESPAÑA & PIRINEOS & DORDOÑA & \begin{tabular}{|c|} 
OTRAS \\
REGIONES
\end{tabular} \\
\hline $\begin{array}{l}\underbrace{}_{v \mid a} \\
I_{v \mid c}\end{array}$ & & & 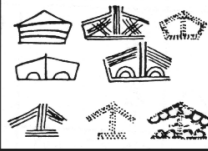 & :::: \\
\hline 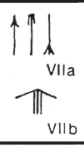 & $\begin{array}{l}\uparrow+ \\
\Rightarrow \mathbb{N}\end{array}$ & $\uparrow \downarrow$ & 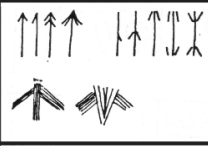 & \\
\hline$\uparrow_{\text {VIII }}^{\uparrow}$ & 造娄鸟 & 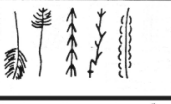 & 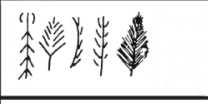 & 数 $>$ \\
\hline 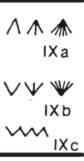 & $\begin{array}{l}\wedge \mathbb{A} \\
\vee \forall r k \\
w\end{array}$ & $\begin{array}{l}\Lambda \hat{\lambda} \wedge \wedge \| \\
\| \vee \\
\text { minn }\end{array}$ & $\begin{array}{l}\wedge \hat{\lambda} \uparrow \\
\vee \propto \Psi \| \Psi \\
\approx \approx W\end{array}$ & $\begin{array}{l}1 \\
W\end{array}$ \\
\hline$+x_{x}$ & $x$ & & $x x_{x}^{x} *$ & + \\
\hline \begin{tabular}{|l|l|}
$|\|| \mid$ \\
$x_{1}$ \\
\end{tabular} & 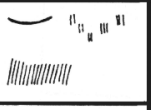 & 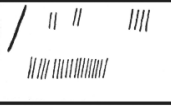 & 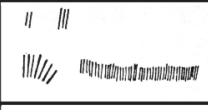 & 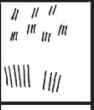 \\
\hline 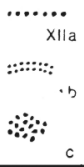 & $a^{n}$ & 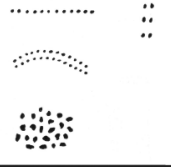 & $\begin{array}{l}\cdots \\
\vdots\end{array}$ & 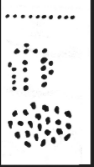 \\
\hline
\end{tabular}

A Figura 5. Clasificación morfológica de G. Sauvet, S. Sauvet y A. Wlodarczyc (1977) VI-XII “Clés”.

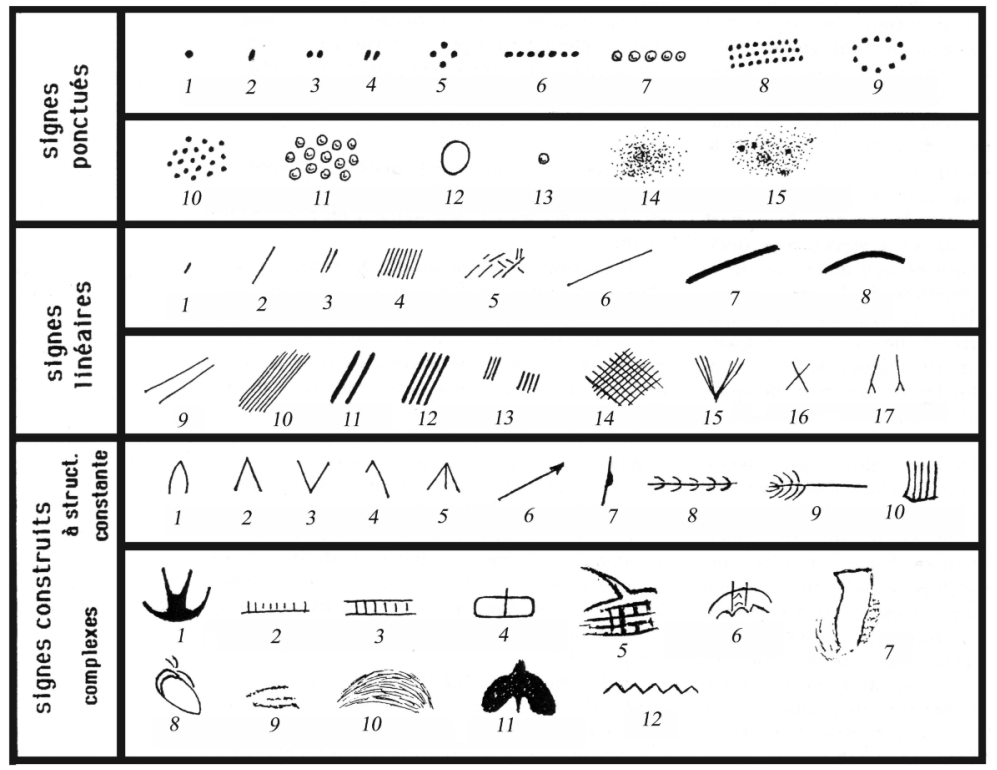

- Figura 6. Clasificación morfológica de D. Vialou para los signos de llas cavernas de L'Ariége (Francia). 


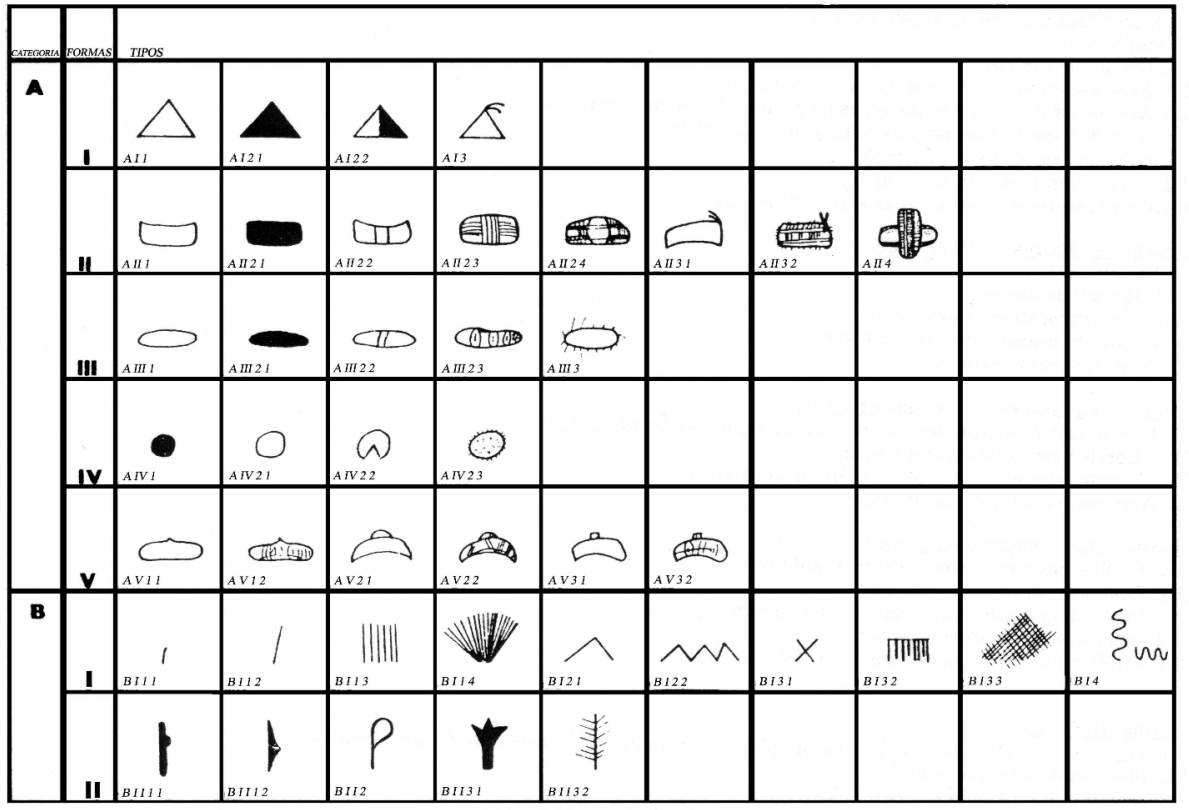

FIgURA 7. Formas de las categorías A y B, definidas por Pilar Casado (1977), con sus tipos. cado en el abanico simbólico de los dispositivos parietales" (Vialou, 1986: 347). Aceptando estos razonamientos, creemos que lo más conveniente en el estudio de los signos de cualquier estación rupestre es edificar una clasificación centrada en ellos mismos y no insertarlos en formas que posiblemente les puedan constreñir y que no reflejen fielmente la veracidad de estas imágenes.

A pesar de estas reflexiones, que como punto de partida apriorístico son adecuadas y ecuánimes, es curioso como el propio D. Vialou, una vez analizadas las representaciones de las cuevas de l'Ariège (Francia) y contrastados otros trabajos, no duda en afirmar, a posteriori, con relación a los signos que pudieran considerarse más "complejos" (geométricos, con subdivisión interna, claviformes, etc): "El análisis comparativo de los conjuntos regionales magdalenienses [...] evidencia el papel preponderante que juegan ciertos signos en la elaboración gráfica de las identidades culturales" (Vialou, 1996: 8). Ahondando en posibles subdivisiones nacidas de criterios de discriminación "simbólica" se puede hacer mención a la postulada por M. Groenen: "nos parece que una primera distinción debe operarse entre los motivos complejos, como los tradicionales tectiformes de la región de Les Eyzies, los aviformes de la región de Lot-Charente o los cuadrangulares tabicados del Cantábrico, por un lado y los trazados simples, como las puntuaciones, los bastoncillos y las manos frotadas o los trazados indeterminados, por otro" (Groenen, 2000: 43). La razón para esta división estribaría en la regionalización, bastante específica, de los diversos signos del primer grupo y, contrariamente, en la "omnipresencia" no solo geográfica sino también topográfica dentro de las mismas cuevas de los signos del segundo grupo. Para M. Groenen, muchas de estas últimas representaciones responden o pueden ser debidas más a acciones técnicas que expresivas.
Según M. Lorblanchet, esta subcategoría podría alcanzar una cifra de entre un tercio y la mitad de las unidades gráficas plasmadas en el arte parietal paleolítico.

Para ese primer grupo de signos, al que refiere M. Groenen, A. Leroi-Gourhan, que fue el primero en calificarlos como signos "plenos", estimó ya al final de su carrera investigadora que podrian servir como "marcadores étnicos", "cuya repartición regionales podía servir de base a la estimación de la identidad cultural" (Leroi-Gourhan, 1979). Para él, la similitud estilística en representaciones "figurativas" comportaría excesivos riesgos a la hora de identificar posibles "marcadores étnicos". A nuestro juicio, estas reflexiones son bastante acertadas, como más adelante abordaremos.

Los aspectos contextuales, topográficos y técnicos de los signos paleolíticos más "simples" o menos elaborados formalmente gozaron de una importancia variable en la investigación de la primera mitad del siglo XX, en función de su relación de proximidad con las figuras zoomorfas. En caso de no existir una cercanía suficiente, la posibilidad de un discreto e insuficiente análisis se cernía sobre ellos. Es decir, el conjunto de caracteres que proporcionan información sobre estas expresiones (contextos, técnicas, morfologías, etc.) no eran analizados minuciosamente puesto que el interés de los especialistas en ellas era reducido. La aplicación de la teoría explicativa de la magia y de la fecundidad y de cómo ésta valoraba diversos signos es, en gran parte, responsable de esta situación de indiferencia contextual y técnica: "La relación con las figuras de animal ha tenido una gran difusión como uno de los medios explicativos de la magia de la caza para el arte paleolítico ya que muchos de estos signos: líneas en forma de flecha, claviformes, ciertos signos de forma rectangular fueron interpretados como armas o trampas." (Casado, 1977: 15-16). No obstante, creemos que también pueden existir otras razo- 
nes que pueden ayudar a comprender ese aislamiento investigador al que muchas de estas imágenes se han visto sometidas. La dificultad a la hora de su clasificación por esa elevada y variada cifra de signos diferentes existentes, los problemas que acarrea la interpretación de algunos de ellos y la falta de esa mal concebida espectacularidad y "belleza" de algunas representaciones de animales han podido contribuir a convertir esta categoria de representaciones en el "patito feo" de nuestra disciplina. Los trabajos estructuralistas de mediados del siglo pasado transformaron la aproximación a su estudio, como previamente se ha puesto de manifiesto.

\section{REFLEXIONES EN TORNO A LOS DIVERSOS PLANOS DE ANÁLISIS}

Las diferentes categorías temáticas del fenómeno expresivo pleistocénico se localizan, a menudo, en asociación contextual, ocupando los mismos espacios y conformando así áreas de superposición y yuxtaposición. Las características de la pared o el techo (con sus infructuosidades y sus formas sugerentes) donde se ubican las imágenes nos aportan, del mismo modo, gran cantidad de información. Realizar inferencias universales de cualquier orden sobre la globalidad de los signos paleolíticos es, además de una temeridad, un ejercicio de reduccionismo, ya que la heterogeneidad de tales manifestaciones es uno de sus principales rasgos. No obstante, sí se pueden apreciar con la pertinente laxitud algunas tendencias en la disposición de algunas formas. Así, parece constatarse una conexión contextual entre ciertos signos, como los llamados "aflechados" (algunos convergentes), con algunas figuras animales, posibilitando en este caso su interpretación como venablos o heridas y haciendo pensar a los investigadores que se trata de animales heridos (Figura 8). Esta disposición de los signos aflechados sobre los vientres y flancos de los animales es una asociación recurrente y extendida en todas las zonas geográficas donde se presenta este fenómeno. Desde la perspectiva estructuralista de A. Leroi-Gourhan esta situación en concreto es interpretada en su clave de binomio sexual.

$\mathrm{Si}$, con respecto a la globalidad de las representaciones paleolíticas, las asociaciones temáticas universales son dudosas, éstas se hacen más visibles al realizar análisis en ámbitos geográficos más concretos (regiones). De la misma manera, contemplamos relaciones entre los tipos de signos y las topografías de las cavidades. A pesar de la dispar distribución de los espacios en las cavernas y de no poderse establecer un único modelo de configuración del paisaje subterráneo, A. Leroi-Gourhan intentó definir áreas topográficas esenciales y diferenciables en el interior de las cuevas analizando los tipos de representación, las asociaciones, la cantidad de las imágenes, etc., que se documentaban en estos "espacios definidos". De esta forma, distinguió entre paneles centrales, áreas de entrada, divertículos, corredores,

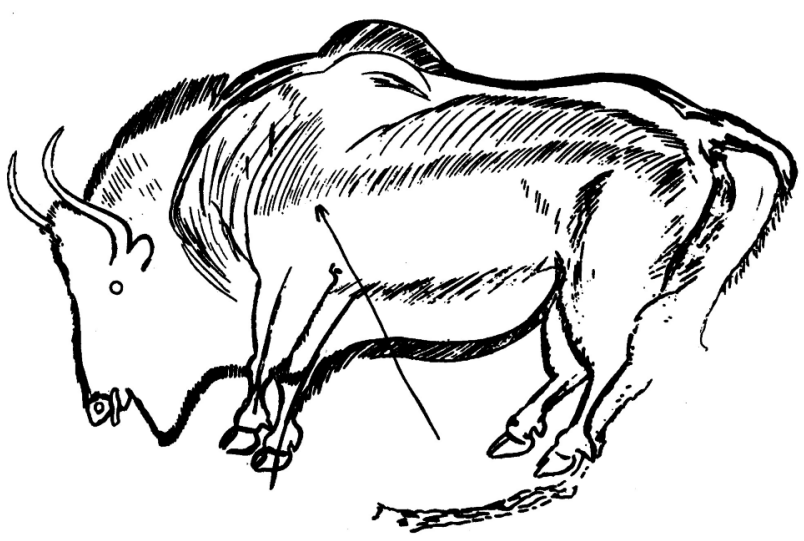

- Figura 8. Bisonte que supuestamente presenta un "proyectil" en su flanco. Cueva de Trois Frères (Ariège, Francia) (Calco H. Breuil).

salas finales, etc. (fig. 9). Esta diferenciación topográfica no se ajusta en un notable número de casos a la realidad: en primer lugar, debido a la falta de uniformidad topográfica de las cuevas; $y$, en segundo, a la contrastación, en la mayoría de ocasiones, de que su modelo ideal de disposición de figuras no se verifica en las cuevas con arte paleolítico. En cambio, sí se identifican áreas que coinciden con divertículos y camarines, algunas de difícil acceso, donde se localizan conjuntos de signos. Éste sería el caso del divertículo de los "escaleriformes" en rojo de Altamira, el camarín de los "tectiformes" o rectangulares rojos con división interna de El Castillo (fig. 10), el camarín de los signos vulvares de Tito Bustillo, los claviformes de La Cullalvera, etc. Es muy posible que los distintos espacios cavernarios albergasen un contenido/valor ideológico o religioso diferencial para las culturas responsables del fenómeno expresivo paleolítico. Para algunos autores (entre ellos A. Leroi-Gourhan 1958a), ciertos signos (generalmente los puntos, líneas y trazos) localizados en corredores y pasillos podrían señalar o advertir topográficamente la entrada en un lugar peligroso, el anuncio de un panel con figuras, el fin de un corredor, etc. "A primera vista, éstos muy numerosos puntos o bastoncillos pintados solos 0 en línea, en paquetes, próximos a las figuras o en los grupos centrales, no parecen distribuidos al azar; parece, por lo tanto, que su presencia en los inicios y fin del santuario, en los pasos entre sus distintas partes o cara a los divertículos en los que se disimulan figuras, son producto de intención deliberada. Varias veces el abate Breuil ha mencionado estas marcas en Niaux, que interpretaba como "paneles de advertencia" y parecían señalar los peligros de la cueva [...] lo que parece claro es que se tiende a la unidad del dispositivo funcional, con sus marcas de entrada y de fondo, sus marcas de advertencia y sus superficies de contornos inacabados" (Leroi-Gourhan, 1958a; citado en 1984: 362-364, 369). Más recientemente, M. Groenen también ha apuntado en esta dirección al referirse a estas representaciones concretas: "al- 
gunos trazados, por el contrario, se situaron aisladamente en lugares de confluencia de las galerias subterráneas: podrian servir como señales que aportaran indicaciones sobre el recorrido a efectuar" (Groenen, 2000: 44).

En el plano técnico, las representaciones de signos corren paralelos al resto de los temas de esta iconografía. Para P. Casado (1977), que estudió de forma general los signos paleolíticos en la Península lbérica, "se observa un predominio de la pintura sobre el grabado y dentro de la primera, del color rojo sobre el negro y el amarillo". Para esta especialista, los signos grabados aparecen tan solo de forma aislada y considera como más "asequible" para esta técnica las líneas, las retículas y los "macarroni". Es factible que la elección de las técnicas responda, además de a un contenido meramente cultural o simbólico, a la decisión del autor en base al tipo y características del soporte donde se quiere realizar la imagen. Las diferentes técnicas utilizadas pueden ser también indicativas de cronologías diacrónicas en la realización de las representaciones.

\section{LA PROBLEMÁTICA DE LOS TRAZOS "INDETERMINADOS"}

Como una subcategoría dentro de los signos, en nuestra opinión, habría que considerar al conjunto de representaciones conocidas como trazos indeterminados, trazos ininteligibles, trazos inorganizados, trazos no caracterizados, trazos no estructurados, trazos inclasificables, trazos indeterminados, trazos pintados, trazos coloreados, manchas, trazos-manchas, etc.. Apelaciones que, según M. Lorblanchet (1993a: 235), han sido empleadas indistintamente por los prehistoriadores en momentos recientes al referirse al grupo de signos que los investigadores primigenios (H. Breuil, Conde Begoüen, etc.) de-

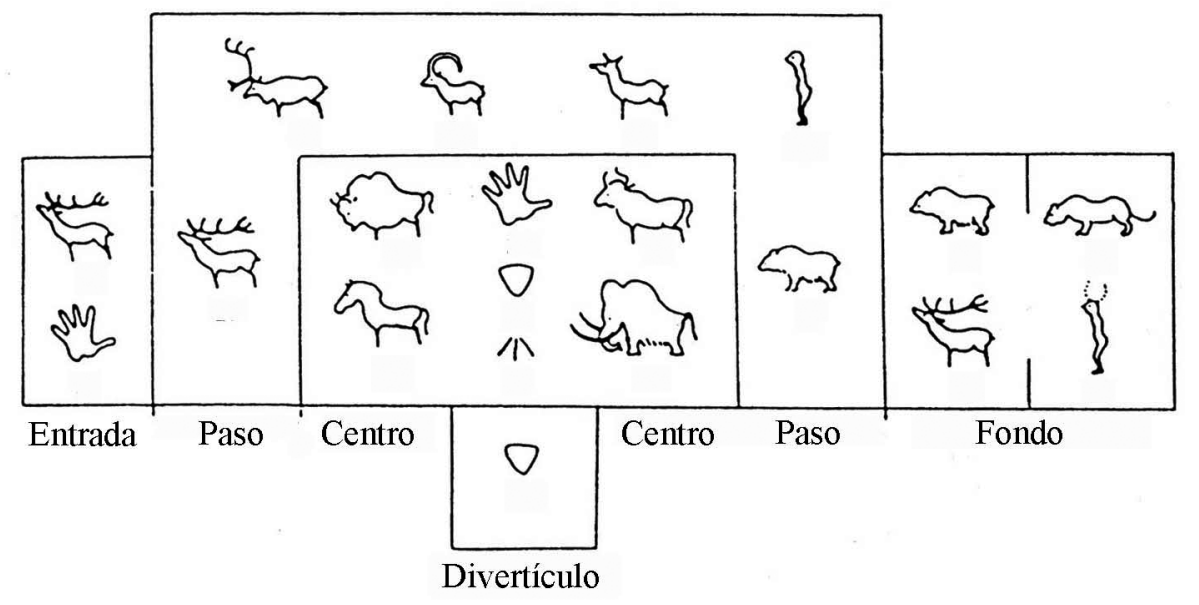

A Figura 9. Esquema del santuario ideal según A. Leroi-Gourhan.

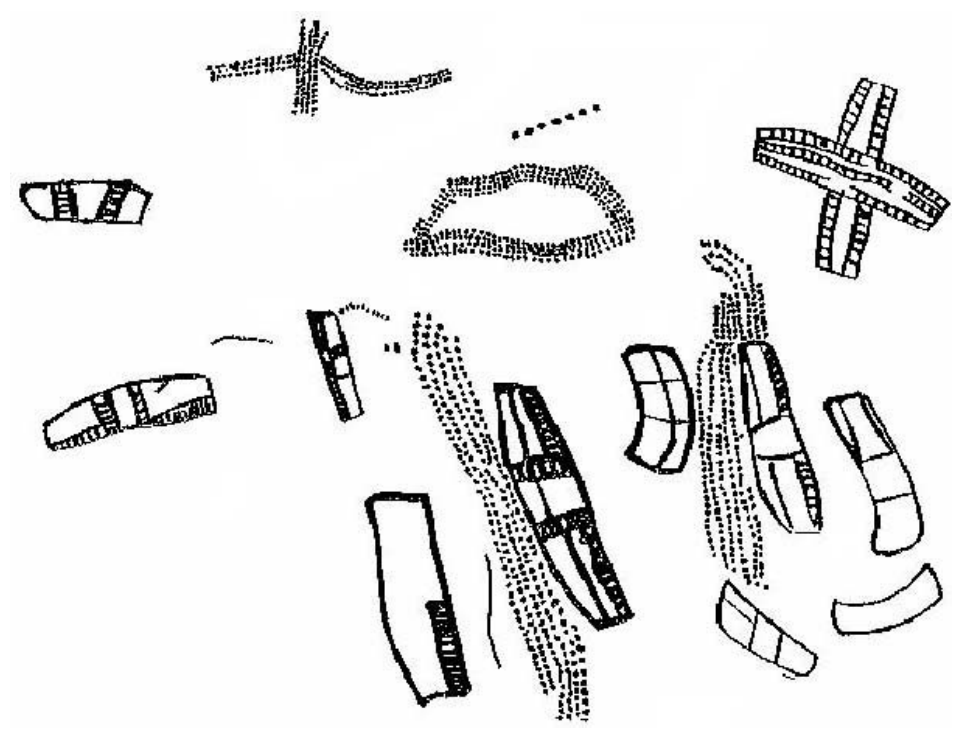

A Figura 10. Signos rectangulares con división interna asociados a bandas de puntuaciones y localizados en el Rincón de los Tectiformes de la cueva de El Castillo (Cantabria), según H. Alcalde del Río et al., (1911). 
nominaban "trazos parásitos". Como vemos, los adjetivos para definir estos trazos son muchos y la unanimidad de un uso consensuado de alguno de ellos, con la debida discriminación de otros, por parte de los especialistas, está ausente. En un estudio dedicado expresamente hacia estas manifestaciones, M. Lorblanchet no solo hace patente el problema y la dificultad que existen al abordar la caracterización y denominación de estos "grafismos heterogéneos", como él les llama, sino que también propone una definición plausible y ajustada a la realidad de éstos: "los trazos indeterminados son trazos o manchas polimorfas, generalmente múltiples, a menudo retorcidos y superpuestos, aparentemente desprovistos de toda organización interna" (Lorblanchet, 1993: 235). Se constata, así, la gran variedad de este conjunto de trazos, a pesar de la semejanza formal por "exclusión" (del resto de signos) que existe entre todos ellos (fig. 11).

No obstante, y contrariamente a lo que se cree, el límite entre los trazos indeterminados y las otras categorias de motivos no es siempre fácil de fijar objetivamente. Su presencia es frecuente en gran parte de las estaciones con arte parietal paleolítico y es aún mayor en el arte mobiliar. Tienen una relación estrecha con otras categorías temáticas al presentarse, a menudo, asociados a ellas, si bien, en un buen número de ocasiones se localizan aislados. Algunos especialistas, entre ellos H. Breuil (1952), A. Laming-Emperaire (1962), A. Leroi-Gourhan (1965), L. Pales (1969), D. Vialou (1986), etc., han juzgado estas manifestaciones posicionándolas dentro de rangos confusos morfológicos, te- máticos y de significado. Es curioso asistir a las afirmaciones que realiza al respecto $A$. Leroi-Gourhan cuando se refiere a ellos: "graffiti mejor que obra de arte", y los compara con los "garabatos que se trazan escuchando en el teléfono" (LeroiGourhan, 1965; citado en M. Lorblanchet, 1993: 239).

La intencionalidad de estos trazos ha sido igualmente debatida. Mientras que muchas manifestaciones evidencian una notoria y buscada morfología, per se, en otras oportunidades parecen más bien ser el fruto de la regularización del soporte (paredes, techos, fragmentos óseos, etc.) para posteriormente plasmar otras figuraciones. A. Laming-Emperaire (1962) fue la primera especialista que se planteó seriamente las dificultades interpretativas que suscitan estos "trazos" en cuanto a su posible involuntariedad o su intencionalidad. En la actualidad, han cobrado protagonismo, aunque siempre es variable en función de la representatividad que supongan en cada conjunto. Hoy por hoy, es innegable el reconocimiento de su valor expresivo o simbólico (Foucher, 1989).

\section{LOS SIGNOS, EL ARTE PALEOLÍTICO Y LA TERRITORIALIDAD: UN ENFOQUE INTERESANTE Y AL ALZA}

Aunque no se trate realmente de una interpretación, en los últimos años se viene utilizando el arte paleolítico, y dentro de éste fundamentalmente se apela a los signos, para identificar territorios de explotación de un mismo grupo pleistocénico: "Los signos, cuyo valor muchas veces es el de

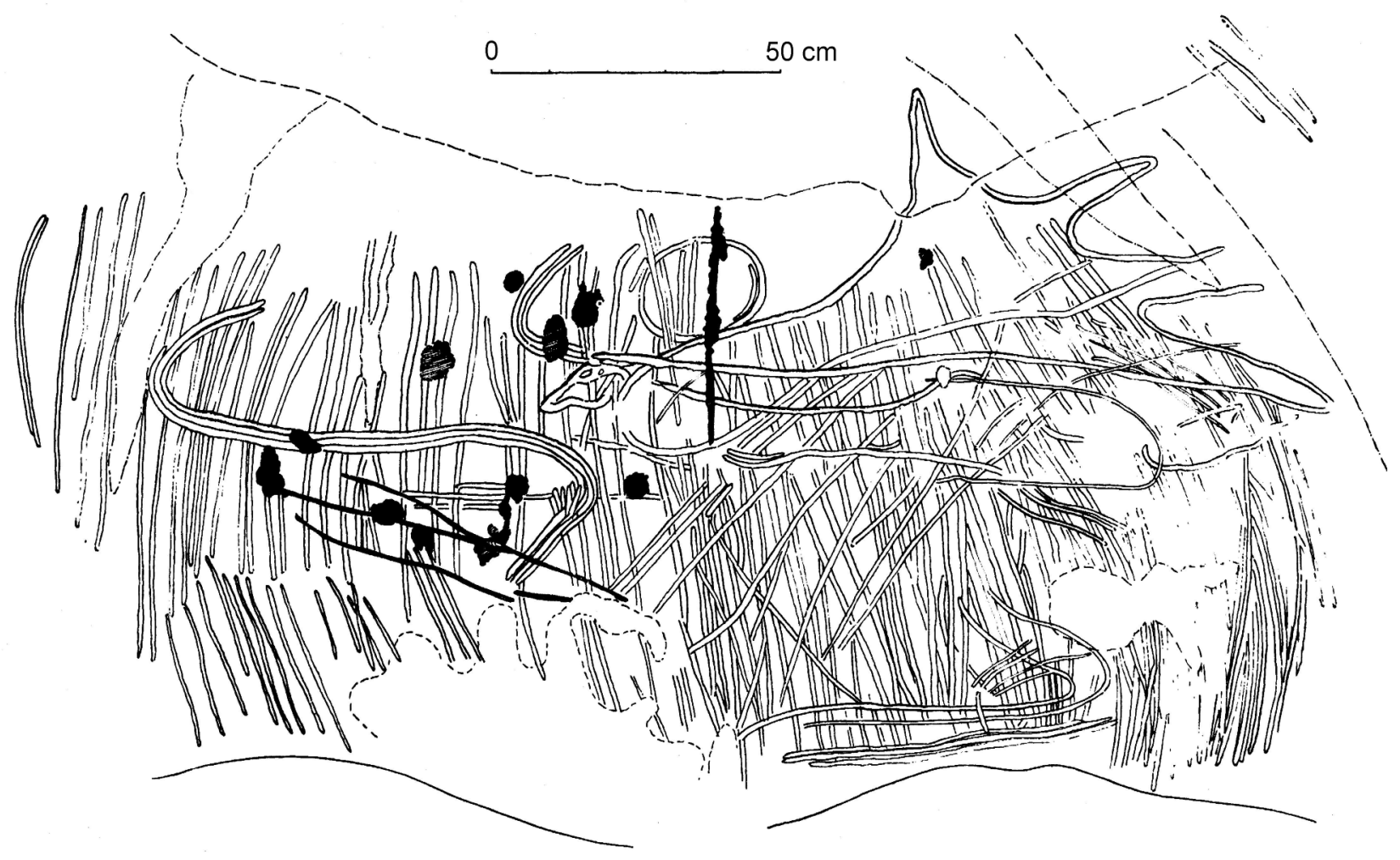

- Figura 11. Panel con trazos "indeterminados grabados" de la cueva de Font de Gaume (Perigord, Francia). 
ayudar a establecer territorios..." (Alcolea y Balbín, 2003: 251); "En lo que respecta a la iconografía, y pese a lo problemático de la interpretación, son los signos los que con más facilidad pueden actuar como referente de relación" (Moure, 1994: 327); "En el arte paleolítico, pueden intuirse un fenómeno similar (territorialidad) en la proliferación o ausencia de cierto tipo de signos y en la acumulación de elementos aparentemente secundarios dentro del conjunto parietal" (Fdez-Tresguerres, 2003: 258). Como ya comentamos, el primero en plantear seriamente la relación arte-signos-territorialidad fue A. Leroi-Gourhan (1958b), si bien fue al final de su carrera cuando más desarrolló esta vía de investigación (Leroi-Gourhan, 1978; 1979; entre otros), llegando a calificar a algunos signos plenos de su clasificación (tectiformes, aviformes, claviformes, etc.) como verdaderos marcadores étnicos.

En 1994, A. Moure, en un magnifico artículo para el brillante número especial de Complutum en homenaje a los profesores M. Fernández Miranda y C. Martín de Guzmán y dedicado al Arte Paleolítico, penetró en las posibilidades que esta aproximación de estudio podía ofrecer, llegando a reveladoras conclusiones. Según él, varios aspectos del arte paleolítico se pueden poner en relación con la movilidad, territorialidad y organización social de los cazadores-recolectores (Moure, 1994: 316).

En su estudio, identifica algunas concordancias iconográficas, técnicas y estilísticas de las representaciones figurativas y no figurativas de varias estaciones rupestres situadas entre el rio Asón y el Sella, y cruza estos datos con los provenientes de los lugares de ocupación (periodos culturales documentados, restos materiales, industrias lítica y ósea, y fundamentalmente la especialización en la caza y la disponibilidad de las materias primas) para sostener la constatación de una división geográfica, de estrategia económica y de utilización de materia prima entre los grupos paleolíticos de la parte astur-cantábrica y el País Vasco, que además se corrobora en sus manifestaciones expresivas gráficas (Moure, 1994: 326-327). Los paralelos de ciertos signos rupestres le proporcionan argumentos de peso para apoyar sus hipótesis. Entre los más importantes se hallan la presencia de "signos de estilo IV" (incluye los signos rectangulares y cuadrangulares) en esta área. Para él, se trata de un territorio con una singularidad expresiva e ideológica definida: "conviene subrayar la personalidad artística del tramo cantábrico situado en los aproximadamente $90 \mathrm{~km}$ de franja que hay entre el Sella y el Pas, y muy especialmente en el Oriente de Asturias (45 km entre el Sella y el Deva). La presencia de determinados signos parietales que faltan fuera de la misma y la concentración de otros referentes estilísticos (como las conocidas ciervas tipo Castillo-Altamira) atestigua la movilidad y/o intercambio de ciertos grupos dentro de esos territorios" (Moure, 1994: 327).

A partir de este trabajo, otros equipos investigadores han llevado a cabo estudios centrados en la identificación de las áreas de movilidad (territorialidad) de los grupos humanos paleolíticos basándose en las características e interpretación de los restos arqueológicos presentes en los yacimientos $y_{\text {, }}$ fundamentalmente, en las similitudes de las evidencias artísticas. M. Menéndez y su equipo, por ejemplo, han advertido la existencia de un grupo paleolítico que "debió moverse por la cuenca fluvial del río Sella con la base residencial en el conjunto de yacimientos del entorno marino de Ribadesella y el apoyo logístico en los yacimientos de un interior no costero pero muy accesible por distancia y orografía, con recursos complementarios" (Menéndez, 2003: 197). Entre las analogías que detectan se encuentra la similar tipología de los "tectiformes" de El Buxu (en su gran mayoría grabados) con algunos de Tito Bustillo (principalmente dispuestos en el panel central) (fig. 12).

En nuestra investigación, también hemos advertido una cierta uniformidad icónica en la región central de Cantabria (en el territorio comprendido entre el valle del Pas, el sistema Saja-Besaya, el valle de Camargo, la ría de la Rabía, llegando hasta el valle del río Pontones) a principios del Magdaleniense que se manifestaría en:

- la presencia de los rectángulos subdivididos en las citadas cuevas (algunos datados en torno al 15.000 BP como en Altamira y Chimeneas);

- los omóplatos y paredes grabados con cérvidos de trazo estriado en Altamira, Castillo, Juyo, Rascaño, El Pendo o El Cierro;

- la existencia de las denominadas "máscaras" en las galerias fínales de Castillo y Altamira, y próximas a

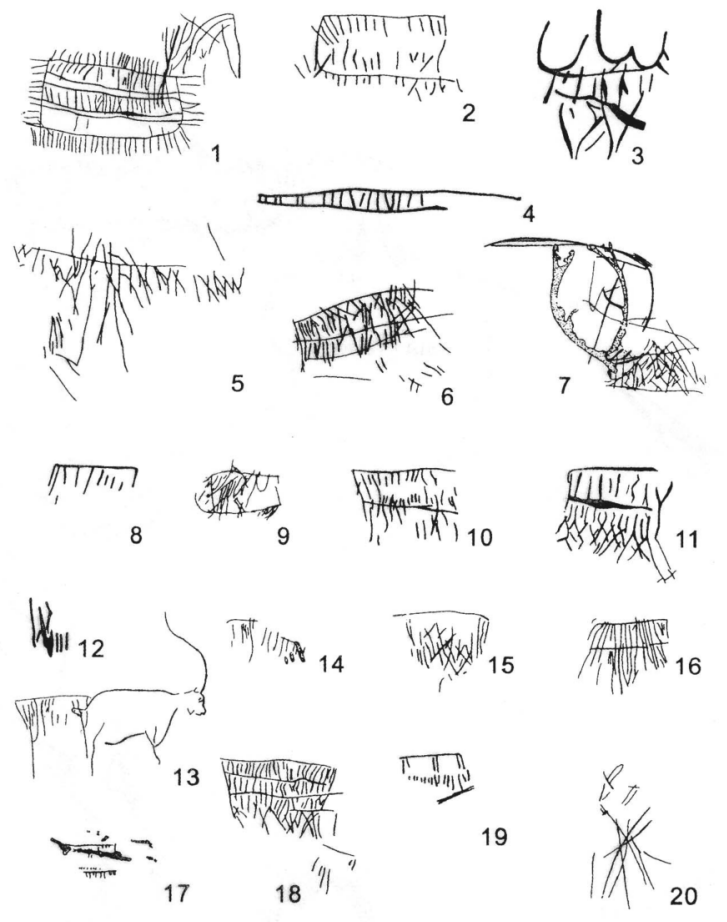

- Figura 12. Serie de signos "tectiformes" de la cueva de El Buxu (Cangas de Onís, Asturias). 
signos rectangulares tabicados negros (quizás podríamos incluir a la máscara del Juyo);

- y en la riqueza formal y similitudes estilísticas de la industria ósea de estas capas (azagayas de sección cuadrada decoradas con motivos semejantes).

Estos constataciones nos inducen a considerar que durante el citado período los yacimientos de Altamira, Castillo, La Garma o El Juyo pudieron ser habitados "por grupos con una misma unidad ideológica, que se plasma en modelos iconológicos semejantes" (Bernaldo de Quirós y Mingo, 2005: 226). Junto a estos grandes yacimientos, considerados como lugares de agregación, encontrariamos otros como Rascaño, El Pendo o El Cierro con menor intensidad de ocupación, una base económica algo diferente donde no se constata el predominio aplastante de restos de ciervo como en Altamira y Castillo y sí un mayor equilibrio entre especies e incluso una especialización en cabra, pero por los que también circula- rían estas gentes con parecido universo ideológico y cultural.

La aplicación de los estudios en arte paleolítico, especialmente de los signos, para aproximarnos al conocimiento del aprovechamiento y uso del territorio en períodos pleistocénicos es muy interesante pues se ha revelado, a través de la comparación, como una herramienta fundamental a la hora de valorar y definir no solo la posible sincronía de los conjuntos sino la identificación de un semejante mundo expresivo y por tanto ideológico y/o religioso, lo que puede indicar la movilidad de un grupo o de una serie de bandas que compartiesen una misma cultura material y simbólica. La información proveniente del registro arqueológico puede reforzar la constatación de una territorialidad grupal, o viceversa, los paralelos expresivos pueden fortalecer las conclusiones derivadas de los análisis y comparaciones de los restos materiales. En definitiva, se puede afirmar que nos encontramos ante una propuesta investigadora central en Prehistoria.

\section{BIBLIOGRAFIA}

Alcalde Del Rio, H. Breuil, H. y Sierra, L. (1911): Les cavernes de la Région Cantabrique. Mónaco.

Alcolea GonzÁlez, J. J. y Balbín Behrmann, R. (2003): "El arte rupestre paleolítico del interior penínsular: Elementos para el estudio de su variabilidad regional". En El Arte Prehistórico desde los inicios del siglo XXI. Primer Symposium Internacional de Arte Prehistórico de Ribadesella: 223-254.

Bernaldo de Quirós, F. y Mingo, A. (2005): "La interpretación de los signos". En J. A. Lasheras y J. González Echegaray (eds.). El significado del Arte Paleolítico: 211-228.

BREUIL, H. (1952): Quatre cents siecles d'art parietal. Montignac-Paris. -(1979); primera edición de 1952: Four hundred centuries of cave art. Hacker Art Books. New York.

Casado López, M. P. (1977): Los signos en el arte Paleolítico de la Península Ibérica. Zaragoza.

FernÁndez TresguerRes, J. (2003): "Arte y territorio durante el periodo aziliense en el occidente cantábrico". En El Arte Prehistórico desde los inicios del siglo XXI. Primer Symposium Internacional de Arte Prehistórico de Ribadesella: 225-262.

FOUCHER, P. (1989): Expérience en double aveugle: la grotte de Marsoulas (Haute Garonne). Diplôme d'étude approfondie École pratique des hautes Etudes Sciences sociales. Toulouse.

GonzÁlez Morales, M. R. (1994): "Pero... ¿hubo alguna vez once mil bisontes? Los temas del arte parietal paleolítico de la región cantábrica". Complutum, 5: 291-302.

JORDÁ, F. (1964): "Sobre técnicas, temas y etapas del arte paleolítico de la Región Cantábrica". ZephyrusXV: 5-25. Salamanca.

LAming-EMPeraire, A. (1962): La Signification de l'art rupestre paléolithique. Ed. Picard. Paris.

LAYTON, R. (1987): "The use of Ethnographic Parallels in Interpreting Upper Paleolithic Rock Art". En L. Holy (ed.). Comparative Anthropology: 210-239. Blackwell.

LEROI-GOURHAN, A. (1958a): "La fonction des signes dans les sanctuaires paléolithiques". Bulletin de la Société Préhistorique Française, LV: 313-317.

-(1958b): "Le symbolisme des grands signes dans l'art pariétal paléolithique". Bulletin de la Societé Préhistorique Française, LV: 307-321.

-(1965): La Préhistoire de l'art occidental. Paris.
-(1978) : «Les signes geometriques dans l'art paléolithique (France-Espagne)». Le Courrier du CNRS, 27: 9-14.

-(1979): "Les signes parietaux comme "marqueurs" ethniques". En Altamira Symposium: 289-294.

-(1984): Símbolos, Artes y Creencias de la Prehistoria. Ediciones Istmo. Madrid.

LoRBLANCHET. M. (1993): "Les tracés indéterminés". En L'art pariétal paléolithique. Techniques et methods d'étude. Comité des travaux historiques et scientifiques du Ministère de l'Enseignement Supérieur et de la Recherche. Documents préhistoriques, 5: 235-241. Paris.

MenÉndeZ FernándeZ, M. (2003): "Arte prehistórico y territorialidad en la cuenca del río Sella". En El Arte Prehistórico desde los inicios del siglo XXI. Primer Symposium Internacional de Arte Prehistórico de Ribadesella:185-200.

Mingo, A. (2007): "El estudio de los signos en el arte rupestre paleolítico: La cueva de El Castillo (Puente Viesgo, Cantabria)". Tesis doctoral inédita. UNED.

Moure Romanillo, A. (1994): "Arte paleolítico y geografías sociales. Asentamiento, movilidad y agregación en el final del Paleolítico cantábrico". Complutum, n.5: 313-330.

PALES, L. (1969): "Les gravures de la Marche I. Félins et Ours, suivis du Félin gravé de la Boliche (Ariège)". Delmas. Bordeaux.

REINACH, S. (1903): "L'art et la magie. A propos des peintures et des gravures de l'age du renne". L'Anthropologie, t.XIV: 258-266. París.

SANCHIDRIÁN, J. L. (1994): "Arte paleolítico de la zona meridional de la península ibérica". Complutum, 5: 163-195 -(2001): Manual de arte prehistórico. Ariel Prehistoria. Barcelona.

SAUVET, G. (1993): "Les signes parietaux". En L'art pariétal paléolithique. Techniques et methods d'étude. Comité des travaux historiques et scientifiques du Ministère de l'Enseignement Supérieur et de la Recherche. Documents préhistoriques, 5 : 219-234.

Sauvet, G. Sauvet, S. y WlodarczYK, A. (1977): "Essai de sémiologie préhistorique (pour une théorie des premiers signes graphiques de I'homme)". Bulletin de la Société Préhistorique Française, t.74, Etudes et Travaux, fascicule 2: 545-558.

VIALOU, D. (1986): L'art des grottes en Ariège Magdalénienne. En XXI suplemento de Gallia Préhistoire. Centre National de la Recherche Scientifique. París. 